\title{
Predictive Markers for Screening Renal Damage in Children with Urinary Tract infections and Vesicoureteral Reflux
}

\author{
Hyeonju Lee, M.D. ${ }^{1 *}$ \\ Jae Hong Choi, M.D. ${ }^{1,2 *}$ \\ Dong-Hyeok Kang ${ }^{3}$ \\ Seunghyo Kim, M.D. ${ }^{1,2}$ \\ Ki-Soo Kang, M.D., Ph.D., ${ }^{1,2}$ \\ Kyoung Hee Han, M.D., ${ }^{1,2}$ \\ 'Department of Pediatrics, Jeju \\ National University Hospital, Jeju, \\ Korea, ${ }^{2}$ Department of Pediatrics, \\ Jeju National University School of \\ Medicine, Jeju, Korea, ${ }^{3}$ Department \\ of Medicine, Jeju National University \\ School of Medicine, Jeju, Korea \\ *These authors contributed equally to this \\ work. \\ Corresponding author: \\ Kyoung Hee Han, M.D. \\ Department of Pediatrics Jeju National \\ University School of Medicine Aran 13gil \\ 15, Jeju, Jeju Special Self-Governing \\ Province 63241, Korea \\ Tel: +82-64-754-8134 \\ Fax: +82-64-727-3114 \\ E-mail: hansyang78@gmail.com
}

Received: 14 February 2020

Revised: 19 March 2020

Accepted: 4 April 2020
Purpose: Urinary tract infections (UTIs) are the most common and serious bacterial infections in children. Therefore, early diagnosis of vesicoureteral reflux (VUR) for treatment planning and the identification of noninvasive markers that can predict renal injury are important in patients with UTIs. We analyzed the clinical features of pediatric UTIs commonly encountered by general practitioners and reinterpreted the blood tests and imaging findings to identify the important clinical predictive markers of VUR in order to selectively perform VCUG.

Methods: This retrospective study was performed among 183 children diagnosed with a UTI or acute pyelonephritis.

Results: The most significant predictor of high grade and bilateral VUR identified using area under the curve analyses was hydronephrosis on kidney ultrasound images with renal cortical defects on dimercaptosuccinic acid (DMSA) kidney scan simultaneously, followed by hydronephrosis only on kidney ultrasound.

Conclusion: The presence of hydronephrosis on kidney ultrasound images or cortical defects or asymmetric kidneys on the DMSA kidney scans can be predictive markers of VUR, reducing the need for VCUG. Our study can thus help minimize the exposure to radiation among patients through selectiveVCUG.

Key words: Urinary tract infection, Children, Vesicoureteral reflux, Predictive marker

\section{Introduction}

Urinary tract infections (UTI) are the most common and serious bacterial infections in children ${ }^{1)}$. Unlike lower UTIs, upper UTIs can cause renal scars and contribute to the development of hypertension and end-stage renal disease if not treated properly ${ }^{2,3)}$. UTIs are known to present many risk factors, especially vesicoureteral reflux (VUR), which is a common malformation found in approximately $30 \%$ of young females with UTIs ${ }^{4}$. VUR can cause recurrent UTIs as well as damage and scarring of the kidneys, which can lead to reflux nephropathy ${ }^{5,6}$. Therefore, early diagnosis and treatment of VUR is critical for a better outcome $\mathrm{e}^{7}$.

To diagnose a VUR, voiding cystourethrography (VCUG) is performed ${ }^{8}$. VCUG facilitates identification of the precise anatomical structures surrounding the bladder as well as diagnosis of related malformations ${ }^{9)}$. However, 
VCUG is an invasive examination that requires fluoroscopy and involves inserting a Foley catheter and injecting a contrast agent. Invasive procedures performed in infants and children are painful, and may worsen the emotional or mental state and physical exhaustion of the caregivers ${ }^{10,11}$. Therefore, it is important to identify noninvasive markers in patients with UTIs that can predict renal injury without the need for VCUG findings ${ }^{12)}$. We analyzed the clinical features of pediatric UTIs commonly encountered by general practitioners and reinterpreted the blood tests and imaging findings to identify the important clinical predictive markers of VUR in order to allow for the selective implementation of VCUG.

\section{Materials and methods}

This retrospective study was performed with 183 children under 15 years of age diagnosed with $1^{\text {st }}$ and recurrent UTIs or acute pyelonephritis between January 1, 2014 and December 31, 2016 at the Jeju National University Hospital in Jeju, Korea.

Symptomatic UTIs in children present as unexplained fever $\geq 38^{\circ} \mathrm{C}$, abnormal urinalysis results such as pyuria, and confirmed diagnosis of significant bacteriuria of $\geq 10^{5}$ colony forming units of bacteria per milliliter $(\mathrm{CFU} / \mathrm{mL})$ in one urine specimen ${ }^{13)}$.

In addition to aseptic pyuria, patients with a suspected UTI on kidney ultrasound and dimercaptosuccinic acid (DMSA) kidney scan were included in this study, while patients with insufficient medical records were excluded from the study.

A urine sample was obtained via midstream collection in toilet-trained children or collected by a catheter or clean catch bag in children who were not toilet-trained. All children were assessed by blood tests (white blood cell, hemoglobin, creatinine, albumin, sodium, c-reactive protein, cystatin $\mathrm{C}$ ), urine tests (urine protein-to-creatinine ratio, urine $\beta_{2}$-microglobulin, urine $\mathrm{N}$-acetyl- $\beta$-D-glucosaminidase), kidney ultrasonography (hydronephrosis, pelvic dilatation, increased renal parenchymal echogenicity, congenital anomalies (i.e. ureter duplication, ureterocele, renal agenesis, multicystic dysplastic kidney), and the DMSA kidney scan (renal cortical defect, functional uptake (\%), right to left functional uptake ratio). For right to left functional ratio on the DMSA kidney scan, a value of $0.81-1.22$ was considered to indicate symmetric kidneys, and values $<0.81$ or $>1.22$ were considered indicators of asymmetric kidneys. In cases of VUR, the degree of VUR was classified based on a grading system by the International Reflux Study in Children ${ }^{14)}$.

A statistical comparison was made between the results of the blood test, urine test, and imaging test regarding identification of VUR. Statistical analysis was performed using SPSS version 18.0 (SPSS Inc., Chicago, IL, USA). The results are expressed as mean $\pm \mathrm{SD}$, and the $t$-test and ANOVA test were used to compare the mean. Linear regression analysis was performed for the prediction of VUR. Receiver operating characteristic curve and area under the curve (AUC) were used to compare the predictive strength of the variables, and $P$ values of less than 0.05 were considered significant.

\section{Ethics statement}

The study protocol was approved by the institutional review board at Jeju National University Hospital (IRB file no. 2016-06-006).

\section{Results}

Among the 183 pediatric patients with a febrile UTI, 108 (59\%) were male. The mean age was $10.8 \pm 18.0$ (range, $0-115$ months). Twelve patients (6.6\%) had a history of UTIs and 2 (1.1\%) had urological surgery. The mean duration of fever

Table 1. Demographic Findings

\begin{tabular}{lc}
\hline & $\mathrm{N}=183$ \\
\hline Age (month) & $10.8 \pm 18.0(0-115)$ \\
$0-3$ mo & $49(26.8 \%)$ \\
$3-12$ mo & $102(55.7 \%)$ \\
$12-48$ mo & $23(12.6 \%)$ \\
$>48$ mo & $9(4.9 \%)$ \\
Gender & $108(59 \%)$ \\
Male & $75(41 \%)$ \\
Female & $12(6.6 \%)$ \\
Previous UTI history & $2(1.1 \%)$ \\
Previous urologic surgery & $3.9 \pm 2.2(1-13)$ \\
Fever duration(days) &
\end{tabular}


was 3.9 \pm 2.2 (range, 1-13 days) (Table 1). Laboratory findings were as follows: white blood cell (WBC), 16,112 $\pm 6,623$

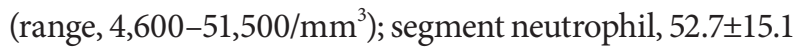
(range, 6.7-91.7\%); albumin, 4.0 \pm 0.3 (range, 3.2-4.6 g/dL); blood urea nitrogen (BUN), 8.9 \pm 3.7 (range, 1.9-32.5 mg/ $\mathrm{dL}$ ); creatinine, $0.5 \pm 0.1$ (range, $0.4-1.7 \mathrm{mg} / \mathrm{dL}$ ); cystatin C, $1.01 \pm 0.24$ (range, $0.54-1.84 \mathrm{mg} / \mathrm{L}$ ); C-reactive protein (CRP), 6.05 \pm 5.69 (range, $0.03-28.73 \mathrm{mg} / \mathrm{dL}$ ); and urine $\beta_{2}$ microglobulin, $1.57 \pm 5.02$ (range, $0.02-40.00 \mathrm{mg} / \mathrm{L}$ ) (Table

\begin{tabular}{|c|c|c|}
\hline Laboratory results & Mean $\pm S D$ & (Range) \\
\hline WBC & $16,112 \pm 6,623 / \mu \mathrm{L}$ & $(4,600-51,500)$ \\
\hline Neutrophil & $52.7 \pm 15.1 \%$ & $(6.7-91.7)$ \\
\hline $\mathrm{Hb}$ & $11.2 \pm 1.1 \mathrm{~g} / \mathrm{dL}$ & $(6.5-16.8)$ \\
\hline PLT & $368 \pm 107 \times 10^{3} / \mu \mathrm{L}$ & (139-758) \\
\hline Total protein & $6.2 \pm 0.4 \mathrm{~g} / \mathrm{dL}$ & $(5.1-7.3)$ \\
\hline Albumin & $4.0 \pm 0.3 \mathrm{~g} / \mathrm{dL}$ & $(3.2-4.6)$ \\
\hline BUN & $8.9 \pm 3.7 \mathrm{mg} / \mathrm{dL}$ & $(1.9-32.5)$ \\
\hline $\mathrm{Cr}$ & $0.5 \pm 0.1 \mathrm{mg} / \mathrm{dL}$ & $(0.4-1.7)$ \\
\hline Cystatin C & $1.01 \pm 0.24 \mathrm{mg} / \mathrm{L}$ & $(0.54-1.84)$ \\
\hline Total calcium & $10.2 \pm 0.5 \mathrm{mg} / \mathrm{dL}$ & (8.9-11.5) \\
\hline Phosphorus & $5.3 \pm 1.0 \mathrm{mg} / \mathrm{dL}$ & $(2.2-7.2)$ \\
\hline $\mathrm{Na}$ & $136 \pm 2 \mathrm{mmol} / \mathrm{L}$ & $(120-142)$ \\
\hline K & $4.8 \pm 0.6 \mathrm{mmol} / \mathrm{L}$ & $(3.5-6.8)$ \\
\hline $\mathrm{Cl}$ & $104 \pm 3 \mathrm{mmol} / \mathrm{L}$ & $(95-112)$ \\
\hline $\mathrm{HCO}_{3}^{-}$ & $21 \pm 2 \mathrm{mmol} / \mathrm{L}$ & $(15-26)$ \\
\hline Uric acid & $3.6 \pm 1.0 \mathrm{mg} / \mathrm{dL}$ & $(1.6-6.4)$ \\
\hline CRP & $6.05 \pm 5.69 \mathrm{mg} / \mathrm{dL}$ & $(0.03-28.73)$ \\
\hline Urine protein to $\mathrm{Cr}$ & $1.97 \pm 3.32 \mathrm{mg} / \mathrm{mg} \mathrm{Cr}$ & $(0.00-24.93)$ \\
\hline Urine NAG & $44.0 \pm 40.4 \mathrm{IU} / \mathrm{g} \mathrm{Cr}$ & $(2.4 \pm 296.1)$ \\
\hline Urine $\beta_{2}$-microglobulin & $1.57 \pm 5.02 \mathrm{mg} / \mathrm{L}$ & $(0.02-40.00)$ \\
\hline
\end{tabular}

Abbreviations: BUN, blood urea nitrogen; $\mathrm{Cr}$, creatinine; $\mathrm{CRP}, \mathrm{C}$-reactive protein; $\mathrm{Hb}$, hemoglobin; NAG, $\mathrm{N}$-acetyl- $\beta$-D-glucosaminidase; PLT, platelet; WBC, white blood cell.

Table 3. Frequency of Culture Proven Uropathogens

\begin{tabular}{llc}
\hline & & $\mathrm{N}=183(\%)$ \\
\hline Urine culture & No growth & $35(19.1)$ \\
& Isolated & $148(80.9)$ \\
& E.coli & $131(88.5)$ \\
& Klebsiella sp. & $10(6.8)$ \\
& Enterobactersp. & $4(2.7)$ \\
Blood culture & Others & $3(2.0)$ \\
& Isolated & $10(5.5)$ \\
ESBL+ & E.coli & $9(90.0)$ \\
\hline Kbbrebsiellasp. & $1(10.0)$ \\
\hline
\end{tabular}

Abbreviation: ESBL, extended-spectrum beta-lactamases.
2).

In our sample of 183 patients, urine cultures were identified in 148 patients (80.9\%): E. coli in 131 patients (88.5\%), Klebsiella sp. in 10 patients (6.8\%), Enterobacter sp. in 4 patients (2.7\%), and other bacteria in 3 patients (2.0\%). Meanwhile, 10 patients (5.5\%) were identified by positive blood culture: E. coli in 9 patients (90\%) and Klebsiella sp. in 1 patient $(10 \%)$. In all, 32 patients (21.6\%) tested positive for extended-spectrum beta-lactamases (Table 3).

The mean age of males was lower than that of females $(P=$ 0.001) (Fig. 1). The duration of fever was higher in older children $(P=0.003)$ and in patients with cortical defects on the DMSA kidney scan $(P=0.000)$. However, the presence of VUR was not significantly associated with duration of fever $(P=0.095)$ (Fig. 2).

All patients in our study underwent kidney ultrasonography. Increased parenchymal echogenicity in right and left kidneys on renal ultrasound was observed in 68 patients (37.2\%) and 66 patients (36.1\%), respectively. Hydronephrosis in right and left kidneys was diagnosed in 12 cases (6.6\%) and 17 cases (9.3\%), respectively. Also, renal agenesis in the right and left kidneys was diagnosed in 1 case $(0.5 \%)$ and 1 case $(0.5 \%)$, respectively. Additionally, neurogenic bladder and ureterocele were found in 1 patient $(0.5 \%)$ and 1 patient $(0.5 \%)$, respectively (Table 4 ).

The laboratory results of patients with hydronephrosis revealed higher serum levels of cystatin $\mathrm{C}(P=0.002)$, phosphorus $(P=0.014)$, and potassium $(P=0.009)$ and a lower urine level of $\beta_{2}$-microglobulin $(P=0.003)$ than patients without hydronephrosis (Fig. 3).

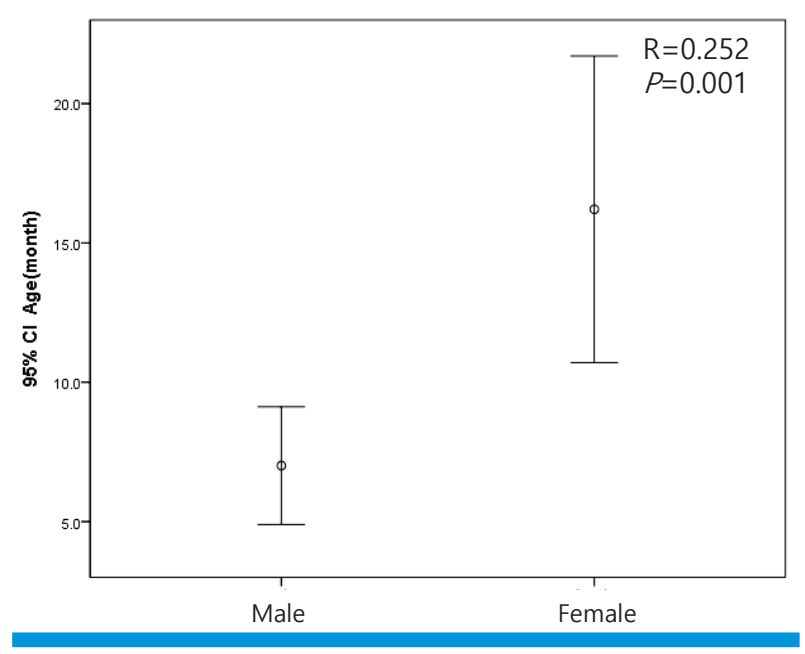

Fig. 1. Relationship between sex and age in urinary tract infections. 
DMSA kidney scan was performed in 152 patients. Their mean functional ratio was $51.0 \pm 6.6$ in the right kidney and $49.0 \pm 6.6$ in the left kidney. Unilateral cortical defects were detected in 76 patients (50\%) and bilateral cortical defects in 14 patients (9.2\%). Cortical defects were found in $48 \mathrm{pa}$ tients (31.6\%) in the right kidney and 56 patients (36.8\%) in the left kidney. Right to left functional ratio was $1.1 \pm 0.8$ (range, 0.3-1.0) (Table 5).

In patients with cortical defects on the DMSA scan, WBC

Table 4. Renal Ultrasound Findings in Patients with UTIs

\begin{tabular}{lcc}
\hline \multirow{2}{*}{ Findings } & \multicolumn{2}{c}{$\mathrm{N}=183$ (\%) } \\
\cline { 2 - 3 } & Right kidney & Left kidney \\
\hline Increased parenchymal echogenicity & $68(37.2)$ & $66(36.1)$ \\
Parenchymal swelling & $20(10.9)$ & $25(13.7)$ \\
Pelvic dilatation & $28(15.3)$ & $79(43.2)$ \\
Hydronephrosis & $12(6.6)$ & $17(9.3)$ \\
Cortical thinning & $4(2.2)$ & $3(1.6)$ \\
Renal agenesis & $1(0.5)$ & $1(0.5)$ \\
Ureter duplication & $1(0.5)$ & $3(1.6)$ \\
Distal ureter dilatation & $26(14.2)$ & $25(13.7)$ \\
Neurogenic bladder & \multicolumn{2}{c}{$1(0.5)$} \\
Ureterocele & \multicolumn{2}{c}{$1(0.5)$} \\
\hline
\end{tabular}

Abbreviation: UTI, urinary tract infection.

Table 5. ${ }^{99 \mathrm{~m}} \mathrm{Tc}$-DMSA renal scan findings in patients with UTIs

\begin{tabular}{lcc}
\hline \multirow{2}{*}{ Findings } & \multicolumn{2}{c}{$\mathrm{N}=152(\%)$} \\
\cline { 2 - 3 } & Right kidney & Left kidney \\
\hline Functional ratio & $51.0 \pm 6.6$ & $49.0 \pm 6.6$ \\
Cortical defect & $48(31.6)$ & $56(36.8)$ \\
Unilateral cortical defect & $76(50.0)$ & \\
Bilateral cortical defect & $14(9.2)$ & \\
Right to left functional ratio & $1.1 \pm 0.8(0.3-1.0)$ &
\end{tabular}

Abbreviations: DMSA, Dimercaptosuccinic acid; Tc, Technetium; UTI, urinary tract infection.
( $P=0.000), \mathrm{CRP}(P=0.000), \mathrm{BUN}(P=0.014)$, and urine $\beta_{2}-$ microglobulin $(P=0.028)$ were significantly higher, while serum albumin $(P=0.001)$, chloride $(P=0.001)$, total calcium $(P=0.010)$, and inorganic phosphorus $(P=0.000)$ were significantly lower than in patients without cortical defects (Fig. 4). When comparing the asymmetric and symmetric groups on the DMSA scan, the levels of BUN $(P=0.033), \mathrm{Cr}$ $(P=0.006)$, and CRP $(P=0.003)$ were higher in the asymmetric cases than in the symmetric cases (Fig. 5).

VCUG was performed in 96 patients. Among these, VUR was not detected in 65 patients (67.7\%). Unilateral VUR was detected in 15 patients (15.6\%) and bilateral VUR in $16 \mathrm{pa}$ tients (16.7\%). Low grade or unilateral VUR was detected in 24 patients (25.0\%) and high grade and bilateral VUR in 7 cases (7.3\%) (Table 6). The patients were categorized into 3 groups (no VUR, low grade or unilateral VUR, and high grade and bilateral VUR) and urine $\mathrm{N}$-acetyl- $\beta$-D-glucosaminidase (NAG) $(P=0.048)$ was higher in the high grade and bilateral VUR group than in the other groups. The

Table 6. VCUG Findings in Patients with UTIs

\begin{tabular}{|c|c|c|c|}
\hline \multirow{2}{*}{ Findings } & & \multicolumn{2}{|c|}{$\mathrm{N}=96(\%)$} \\
\hline & & Right kidney & Left kidney \\
\hline \multirow[t]{5}{*}{ Grade } & I & 2 & 4 \\
\hline & $\|$ & 7 & 6 \\
\hline & $\|$ & 4 & 7 \\
\hline & IV & 5 & 8 \\
\hline & V & 2 & 2 \\
\hline Unilateral VUR & & \multicolumn{2}{|c|}{$15(15.6)$} \\
\hline Bilateral VUR & & \multicolumn{2}{|c|}{$16(16.7)$} \\
\hline Low grading or unilateral & & \multicolumn{2}{|c|}{$24(25.0)$} \\
\hline High grading and bilateral & & \multicolumn{2}{|c|}{$7(7.3)$} \\
\hline No VUR & & \multicolumn{2}{|c|}{$65(67.7)$} \\
\hline
\end{tabular}

Abbreviations:VCUG, voiding cystourethrogram;VUR, vesicoureteral reflux.
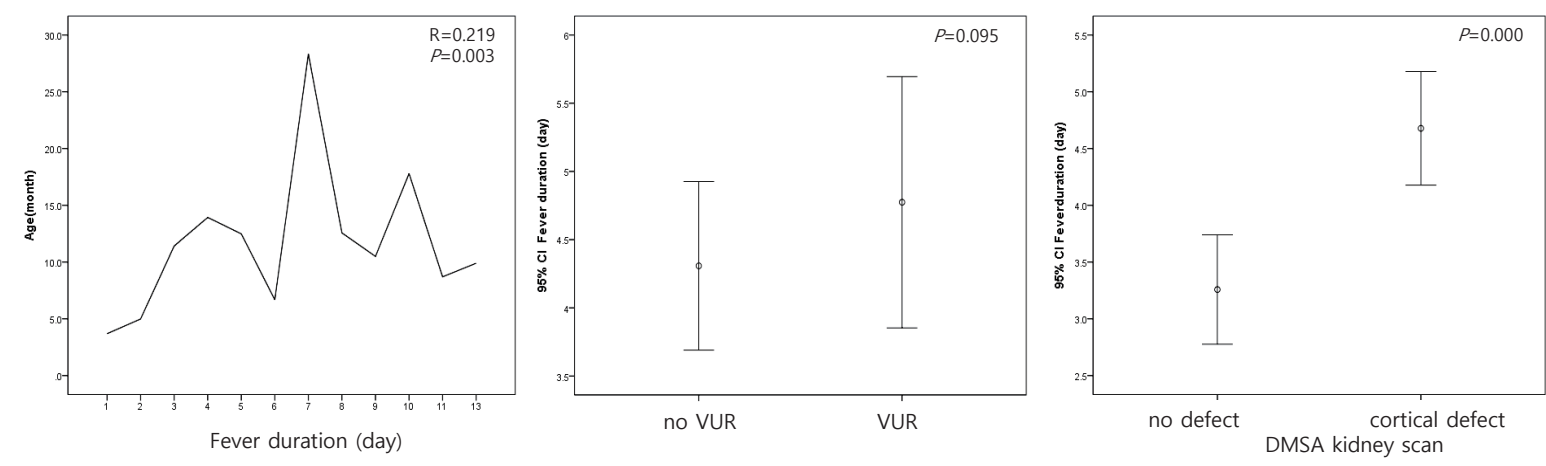

Fig. 2. Clinical factors related to fever duration in urinary tract infections. 
right to left functional ratio was the highest in the group with low grade or unilateral VUR $(P=0.005)$ (Fig. 6).

Linear regression analysis for the prediction of VUR was statistically significant for hydronephrosis in kidney ultrasound images $(P=0.000)$ or cortical defects $(P=0.000)$ or asymmetric kidney $(P=0.049)$ on the DMSA kidney scans (Table 7). The most significant predictors of high grade and bilateral VUR were the presence of hydronephrosis in kidney ultrasound images and cortical defects on the DMSA kidney scan, followed by hydronephrosis only identified using the AUC (Fig. 7).

\section{Discussion}

Hydronephrosis and VUR are well-known risk factors for UTIs in children ${ }^{15-18)}$. In a retrospective single center study on the incidence of UTIs in infants with antenatal diagnosis of hydronephrosis, 24 (13\%) in 192 patients experienced at least one episode of a UTI during the follow-
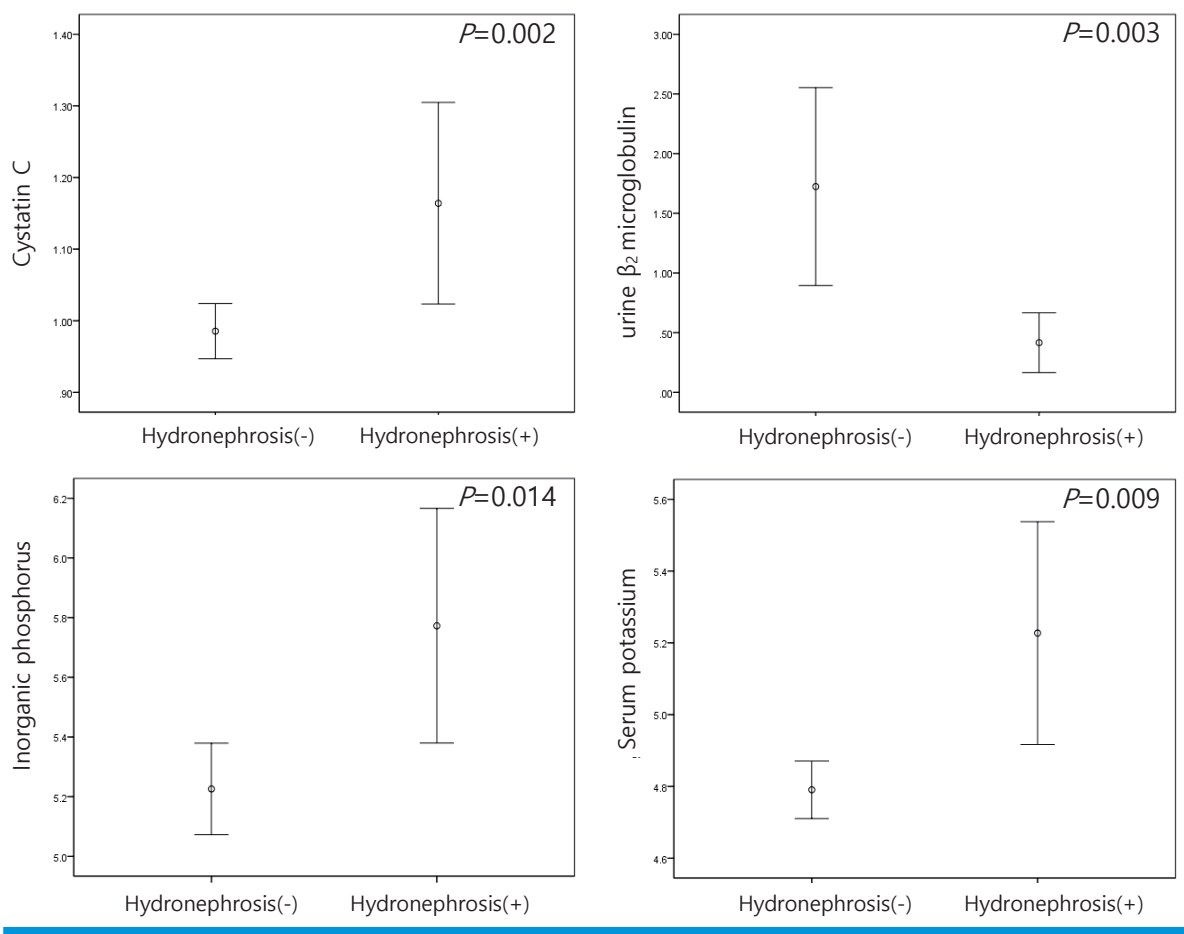

Fig. 3. Laboratory factors related to the presence of hydronephrosis in urinary tract infections.
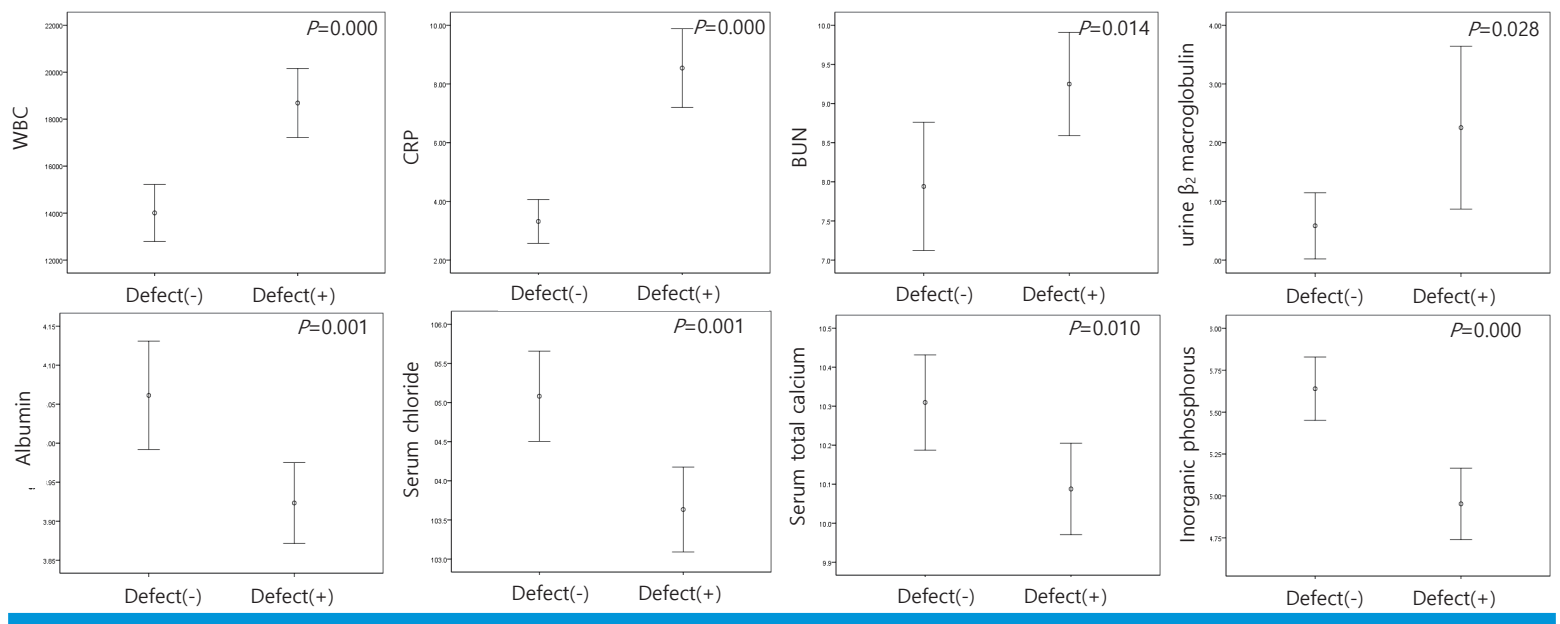

Fig. 4. Laboratory factors related to the presence of cortical defects on the DMSA kidney scan in urinary tract infections. 

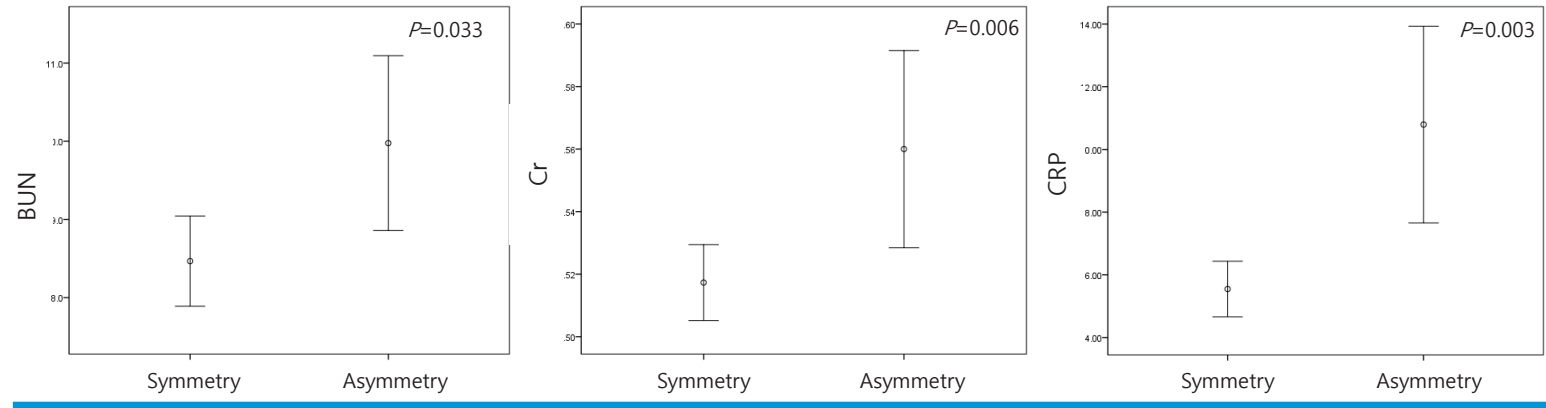

Fig. 5. Laboratory factors related to asymmetric kidney on the DMSA kidney scan in urinary tract infections.
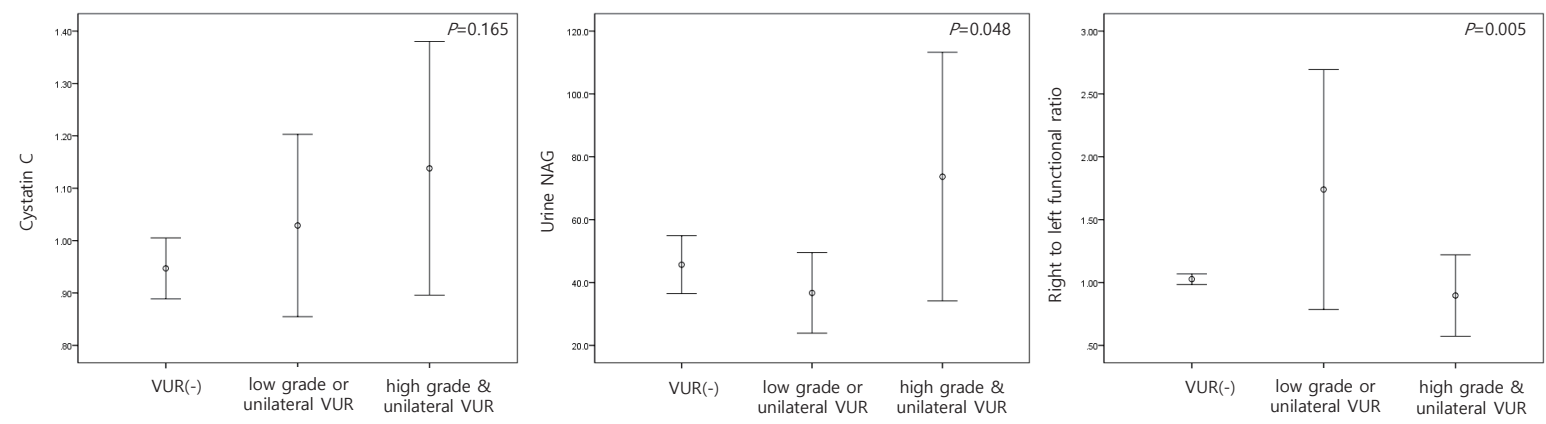

Fig. 6. Laboratory factors related to high grade and bilateral VUR.

Table 7. Linear Regression Analysis of the Variables Associated with VUR

\begin{tabular}{|c|c|c|c|c|c|c|c|c|}
\hline \multirow[t]{2}{*}{ Parameter } & \multicolumn{2}{|c|}{ Unstandardized coefficients } & \multirow{2}{*}{$\begin{array}{c}\begin{array}{c}\text { Standardized } \\
\text { coefficients }\end{array} \\
\beta\end{array}$} & \multirow[t]{2}{*}{$\mathrm{t}$} & \multirow{2}{*}{ Sig. } & \multicolumn{2}{|c|}{$\begin{array}{l}\text { 95\% confidence } \\
\text { interval for B }\end{array}$} & \multirow{2}{*}{$\begin{array}{c}\text { Collinearity } \\
\text { statistics (VIF) }\end{array}$} \\
\hline & B & Standard error & & & & Lower & Upper & \\
\hline Age (month) & 0.003 & 0.005 & 0.082 & 0.664 & 0.509 & -0.007 & 0.013 & 2.219 \\
\hline Gender & -0.262 & 0.137 & -0.208 & -1.915 & 0.059 & -0.534 & 0.010 & 1.738 \\
\hline Urine $\beta_{2}$-microglobulin & -0.012 & 0.011 & -0.106 & -1.045 & 0.299 & -0.034 & 0.010 & 1.513 \\
\hline Hydronephrosis in kidney USG & 0.688 & 0.182 & 0.326 & 3.768 & 0.000 & 0.324 & 1.051 & 1.099 \\
\hline Cortical defects on DMSA scan & 0.381 & 0.095 & 0.474 & 4.016 & 0.000 & 0.192 & 0.570 & 2.052 \\
\hline Asymmetric kidney on DMSA scan & 0.328 & 0.164 & 0.204 & 1.997 & 0.049 & 0.001 & 0.656 & 1.541 \\
\hline
\end{tabular}

R-squared 0.470, Adjusted R-squared 0.429, F statistics 11.509

Abbreviations: VUR, vesicoureteral reflux; DMSA, Dimercaptosuccinic acid.

up period. Among these patients with a UTI, high grade VUR was detected in 15 patients $(63 \%)^{19)}$. Indeed, a different study also suggested that prenatal hydronephrosis with high grade VUR may pose as a risk factor for UTIs ${ }^{20)}$.

Kidney sonography can be used to predict VUR in neonates and infants ${ }^{21-24)}$. In a study on 735 infants diagnosed with mild hydronephrosis, 189 infants $(25.7 \%)$ had VUR. This study also included patients with UTIs, and there was no statistically significant relationship between mild hydronephrosis and the presence of a UTI. However, UTI incidence was significantly higher in patients with VUR grade 3 or higher than in those with a lower grade VUR, regard- less of the presence of hydronephrosis during the follow-up period $^{24)}$. According to another study published in 2008, studies in infants under 3 months of age also found that kidney sonography was statistically significant in predicting the presence of VUR in high grade VUR children ${ }^{25}$.

Alternatively, ultrasonography was used as a screening test for genitourinary anomalies in patients with a $\mathrm{UTI}^{26,27)}$. According to Nelson et $\mathrm{al}^{27}$., 389 (17.2\%) in 2,259 patients who performed kidney ultrasonography were diagnosed with hydronephrosis. Mild hydronephrosis was detected in 298 patients (13.2\%) and high grade hydronephrosis in 91 patients (4.0\%). However, ultrasonography screening of 


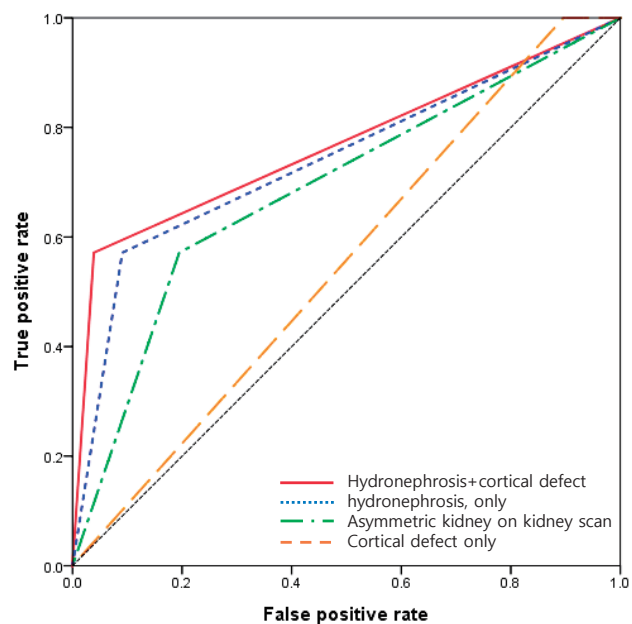

\begin{tabular}{lccccc}
\hline \multirow{2}{*}{$\begin{array}{l}\text { variables } \\
\text { AUC }\end{array}$} & $P$ & \multicolumn{2}{c}{$\begin{array}{c}\text { 95\% confidence } \\
\text { interval }\end{array}$} \\
\cline { 4 - 6 } & & & lower & upper \\
\hline Hydronephrosis+cortical defect & 0.766 & 0.020 & 0.535 & 0.997 \\
hydronephrosis only & 0.740 & 0.036 & 0.512 & 0.969 \\
Asymmetric kidney on kidney scan & 0.688 & 0.100 & 0.463 & 0.913 \\
Cortical defect only & 0.552 & 0.650 & 0.347 & 0.757 \\
\hline
\end{tabular}

Fig. 7. Receiver operating characteristic curve and diagnostic accuracy of biomarkers in the prediction of high grade or bilateral VUR.

genitourinary anomalies such as VUR had low sensitivity and specificity ${ }^{27)}$.

To evaluate UTI patients by imaging, we used "Top-down approach", which focuses on identifying children at risk for pyelonephritis or renal scarring, whether or not VUR is present, performing a DMSA scan during the acute inflammatory phase of UTI. Once renal involvement is demonstrated on the DMSA scan, the patient then undergoes VCUG to find out VUR. Using this method will help reduce unnecessary invasive test of VCUG ${ }^{28,29)}$.

In this study, VCUG was performed in 52\% of UTI patients, $32.2 \%$ of patients with reflux, and only 7 patients ( 3.8 \%) with bilateral or high grade VUR who may need prophylatic antibiotics or urosurgery. Therefore, it is important to find the predictive marker of VUR for selective evaluation.

There are several studies on the prediction of VUR in patients with UTIs showing cortical defects and relative uptake on the DMSA scans ${ }^{30,31)}$. In the Hong et $\mathrm{al}^{30)}$., study, the sample was divided into groups with and without VUR. Although the patients in the group with VUR were older, there was no significant difference between the participants in the control group and VUR group regarding sex, fever duration, WBC count, CRP, and estimated glomerular fil- tration ratio. In the group with VUR, the asymmetric relative uptake was more frequently observed on the DMSA kidney scan. There were no significant differences between the 2 groups in terms of the presence of hydronephrosis, cortical defects on the DMSA kidney scan, and hydronephrosis with simultaneous cortical defect. The sensitivity and specificity of cortical defects on the DMSA kidney scan, suggestive of VUR, were $79 \%$ and 5\%, respectively. The sensitivity and specificity of hydronephrosis in ultrasound images were $39 \%$ and $70 \%$, respectively ${ }^{30)}$.

Snodgrass et $\mathrm{al}^{32)}$, performed a cross-sectional observational study in which VUR was diagnosed in $15.5 \%$ of the 565 patients with cortical defects on the DMSA kidney scans. Additionally, higher grades of VUR have been associated with higher risks of cortical defects on the DMSA kidney scans. Furthermore, UTI recurrence was more frequent in patients with a higher grade of $\mathrm{VUR}^{32}$. Another retrospective study on a pediatric population found that older females ( $>27$ months) with UTIs had more renal scars on the DMSA kidney scans than younger females. Additionally, renal scars were more common in patients with high grades of VUR (IV and V) than in patients with low grades of VUR. However, renal scars in patients with UTIs were not significantly different among unilateral and bilateral VURs ${ }^{33)}$.

Laboratory findings of patients with UTIs in our study were related to inflammatory responses and correlated with cortical defects on the DMSA kidney scan. The severity of the inflammation should be interpreted as a correlation with the cortical defect ${ }^{34)}$, such as acute pyelonephritis. Therefore, it is difficult to predict the presence of VUR based on the severity of the inflammatory response. If hydronephrosis is diagnosed in renal ultrasonography in patients with UTIs, the possibility of VUR should be considered $^{18,21,24)}$. In addition, if UTIs are present in patients with hydronephrosis, cortical defects on the DMSA kidney scans are strongly suggestive of VUR ${ }^{30,311}$. Therefore, in such cases, VCUG should be performed ${ }^{35-38)}$.

Recently, some new biomarkers predicted renal scarring in children with VUR, which included urinary level of neutrophil-gelatinase-associated lipocalin (NGAL), kidney injury molecule-1 (KIM-1), and liver-type fatty-acid-binding protein (L-FABP). The median value of uNAGL/Cr and UL-FABP/Cr was higher in groups with VUR than in 
groups without VUR, and the median value of uKIM-1/Cr was similar in both the groups ${ }^{39)}$. According to a paper published in 2013, there are reports in the literature of urinary tissue inhibitor of metalloproteinase-1 (TIMP1) and matrix metalloproteinase 9 (MMP9) levels being used as predictors of VUR in neonates diagnosed with prenatal hydronephrosis. Indeed, MMP9, MMP9/Cr, MMP9/TIMP1, and MMP9/TIMP1/Cr ratios were higher in patients with VUR than in those without VUR. Based on these results, the authors discussed the use of screening tests for the presence of VUR in neonates with hydronephrosis to reduce their exposure to radiation, as in $\mathrm{VCUG}^{40)}$. Other studies suggests that MMP9 and TIMP1 could be used as biomarkers to predict renal scars in children with UTIs ${ }^{41,42)}$.

The limitation of our study was inclusion criteria including children with 1st attack of UTI as well as with recurrence of UTI. Another limitation was that the definition of UTI according to age based on 12 months of age is not introduced. In our study, children with febrile UTI were retrospectively included as a symptomatic UTI regardless of age.

In conclusion, the presence of hydronephrosis in kidney ultrasound or cortical defects or asymmetric kidney on the DMSA kidney scans can be predictive markers for VUR. Our study can help to minimize exposure to radiation through the selective implementation of VCUG.

\section{Acknowledgments}

This study was supported by a research grant from the Jeju National University Hospital development fund in 2016.

\section{Conflicts of interest}

No potential conflict of interest relevant to this article was reported.

\section{References}

1. Bitsori M, Galanakis E. Pediatric urinary tract infections: diagnosis and treatment. Expert Rev Anti Infect Ther 2012;10:1153-64.
2. Peters C, Rushton HG. Vesicoureteral reflux associated renal damage: congenital reflux nephropathy and acquired renal scarring. J Urol 2010;184:265-73.

3. Elder JS, Peters CA, Arant BS Jr, Ewalt DH, Hawtrey CE, Hurwitz $R S$, et al. Pediatric vesicoureteral reflux guidelines panel summary report on the management of primary vesicoureteral reflux in children. J Urol 1997;157:1846-51.

4. Downs SM. Technical report: urinary tract infections in febrile infants and young children. The urinary tract subcommittee of the American academy of pediatrics committee on quality improvement. Pediatrics 1999;103:e54.

5. Mattoo TK, Mathews R, Gupta IR. Vesicoureteral reflux and renal scarring in children. In: Avner ED, Harmon WE, Niaudet P, et al. Pediatric Nephrology. 7th Ed. Baltimore: Lippincott Williams \& Wilkins; 2016:1716-35

6. Gordon I, Barkovics M, Pindoria S, Cole TJ, Woolf AS. Primary vesicoureteric reflux as a predictor of renal damage in children hospitalized with urinary tract infection: a systematic review and meta-analysis. J Am Soc Nephrol 2003;14:739-44.

7. Peters CA, Skoog SJ, Arant BS Jr, Copp HL, Elder JS, Hudson RG, et al. Summary of the AUA guideline on management of primary vesicoureteral reflux in children. J Urol 2010;184:1134-44.

8. Williams G, Fletcher JT, Alexander SI, Craig JC. Vesicoureteral reflux. J Am Soc Nephrol 2008;19:847-62.

9. Berrocal T, López-Pereira P, Arjonilla A, Gutiérrez J. Anomalies of the distal ureter, bladder, and urethra in children: embryologic, radiologic, and pathologic features. Radiographics 2002;22:113964.

10. Johnin K, Kobayashi K, Tsuru T, Yoshida T, Kageyama S, Kawauchi A. Pediatric voiding cystourethrography: An essential examination for urologists but a terrible experience for children. Int J Urol 2019;26:160-71.

11. Bensman A, Dunand O, Ulinski T. Urinary tract infections. In: Avner ED, Harmon WE, Niaudet P, Yoshikawa N, editors. Pediatric Nephrology. 6th ed. Berlin Heidelberg: Springer-Verlag; 2009. pp. 1299-310

12. Mahyar A, Ayazi P, Mavadati S, Oveisi S, Habibi M, Esmaeily S. Are clinical, laboratory, and imaging markers suitable predictors of vesicoureteral reflux in children with their first febrile urinary tract infection? Korean J Urol 2014;55:536-41.

13. Schmidt B, Copp HL. Work-up of pediatric urinary tract infection. Urol Clin North Am 2015;42:519-26.

14. Lebowitz RL, Olbing H, Parkkulainen KV, Smellie JM, TamminenMöbius TE. International system of radiographic grading of vesicoureteric reflux. International reflux study in children. Pediatr Radiol 1985;15:105-9.

15. Mattoo TK. Vesicoureteral reflux and reflux nephropathy. Adv Chronic Kidney Dis 2011;18:348-54.

16. Huang HP, Lai YC, Tsai IJ, Chen SY, Tsau YK. Renal ultrasonography should be done routinely in children with first urinary tract infections. Urology 2008;71:439-43.

17. Belman AB. Vesicoureteral reflux. Pediatr Clin North Am 1997:44: 
$1171-90$.

18. Zee RS, Herbst KW, Kim C, McKenna PH, Bentley T, Cooper CS, et al. Urinary tract infections in children with prenatal hydronephrosis: A risk assessment from the society for fetal urology hydronephrosis registry. J Pediatr Urol 2016;12:261.e1-7.

19. Visuri S, Jahnukainen T, Taskinen S. Incidence of urinary tract infections in infants with antenatally diagnosed hydronephrosis-A retrospective single center study. J Pediatr Surg 2017;52:1503-6.

20. Braga LH, Farrokhyar F, D'Cruz J, Pemberton J, Lorenzo AJ. Risk factors for febrile urinary tract infection in children with prenatal hydronephrosis: a prospective study. J Urol 2015;193:1766-71.

21. Skoog SJ, Peters CA, Arant BS Jr, Copp HL, Elder JS, Hudson RG, et al. Pediatric vesicoureteral reflux guidelines panel summary report: clinical practice guidelines for screening siblings of children with vesicoureteral reflux and neonates/infants with prenatal hydronephrosis. J Urol 2010;184:1145-51.

22. Brophy MM, Austin PF, Yan Y, Coplen DE. Vesicoureteral reflux and clinical outcomes in infants with prenatally detected hydronephrosis. J Urol 2002;168:1716-9.

23. Logvinenko T, Chow JS, Nelson CP. Predictive value of specific ultrasound findings when used as a screening test for abnormalities on VCUG. J Pediatr Urol 2015;11:176.e1-7.

24. Berrocal T, Pinilla I, Gutiérrez J, Prieto C, de Pablo L, Del Hoyo ML. Mild hydronephrosis in newborns and infants: can ultrasound predict the presence of vesicoureteral reflux. Pediatr Nephrol 2007;22:91-6.

25. Yi DY, Kim NY, Cho HY, Kim JE, Sim SY, Son DW, et al. Prediction of high grade vesicoureteral reflux in infants less than 3 months with urinary tract infection. Child Kidney Dis 2008;12:178-85.

26. Ghobrial EE, Abdelaziz DM, Sheba MF, Abdel-Azeem YS. Value of ultrasound in detecting urinary tract anomalies after first febrile urinary tract infection in children. Clin Pediatr (Phila) 2016;55:41520.

27. Nelson CP, Johnson EK, Logvinenko T, Chow JS. Ultrasound as a screening test for genitourinary anomalies in children with UTI. Pediatrics 2014;133:e394-403.

28. Pohl HG, Belman AB. The "top-down" approach to the evaluation of children with febrile urinary tract infection. Adv Urol 2009: 783409.

29. Jang KM, Lim MH, Park YH, Kim S. Clinical efficacy of a top-down approach for children with a first febrile urinary tract infection. Child Kidney Dis 2017;21:114-20.

30. Hong IK, Chung MH, Bin JH, Lee KY, Kim JS, Kim CH, et al. Prediction of vesicoureteral reflux in children with febrile urinary tract infection using relative uptake and cortical defect in DMSA scan. Pediatr Neonatol 2018;59:618-23.
31. Sheu JN, Wu KH, Chen SM, Tsai JD, Chao YH, Lue KH. Acute 99mTc DMSA scan predicts dilating vesicoureteral reflux in young children with a first febrile urinary tract infection: a population-based cohort study. Clin Nucl Med 2013;38:163-8.

32. Snodgrass WT, Shah A, Yang M, Kwon J, Villanueva C, Traylor J, et al. Prevalence and risk factors for renal scars in children with febrile UTI and/or VUR: a cross-sectional observational study of 565 consecutive patients. J Pediatr Urol 2013;9:856-63.

33. Soylu A, Demir BK, Türkmen M, Bekem Ö, Saygı M, Çakmakçı $H$, et al. Predictors of renal scar in children with urinary infection and vesicoureteral reflux. Pediatr Nephrol 2008;23:2227-32.

34. Orellana P, Baquedano P, Rangarajan V, Zhao JH, Eng ND, Fettich J, et al. Relationship between acute pyelonephritis, renal scarring, and vesicoureteral reflux. Results of a coordinated research project. Pediatr Nephrol 2004;19:1122-6.

35. Riccabona M, Avni FE, Blickman JG, Dacher JN, Darge K, Lobo ML, et al. Imaging recommendations in paediatric uroradiology: minutes of the ESPR workgroup session on urinary tract infection, fetal hydronephrosis, urinary tract ultrasonography and voiding cystourethrography, Barcelona, Spain, June 2007. Pediatr Radiol 2008;38:138-45.

36. Hellström M, Jacobsson B, Mårild S, Jodal U. Voiding cystourethrography as a predictor of reflux nephropathy in children with urinary-tract infection. AJR Am J Roentgenol 1989;152:801-4.

37. Subcommittee on urinary tract infection, Steering committee on quality improvement and management, Roberts KB. Urinary tract infection: clinical practice guideline for the diagnosis and management of the initial UTI in febrile infants and children 2 to 24 months. Pediatrics 2011;128:595-610.

38. Ahmed SM, Swedlund SK. Evaluation and treatment of urinary tract infections in children. Am Fam Physician 1998;57:1573-80.

39. Parmaksız G, Noyan A, Dursun H, İnce E, Anarat R, Cengiz N. Role of new biomarkers for predicting renal scarring in vesicoureteral reflux: NGAL, KIM-1, and L-FABP. Pediatr Nephrol 2016;31:97-103.

40. Mohammadjafari $\mathrm{H}$, Rafiei A, Abedi M, Aalaee A, Abedi E. The role of urinary TIMP1 and MMP9 levels in predicting vesicoureteral reflux in neonates with antenatal hydronephrosis. Pediatr Nephrol 2014;29:871-8.

41. Abedi SM, Mohammadjafari H, Rafiei A, Bazi S, Yazdani P. Urinary matrix metalloproteinase 9 and tissue inhibitor of metalloproteinase 1 biomarkers for predicting renal scar in children with urinary tract infection. Turk J Urol 2017;43:536-42.

42. Chromek M, Tullus K, Hertting O, Jaremko G, Khalil A, Li YH, et al. Matrix metalloproteinase- 9 and tissue inhibitor of metalloproteinases-1 in acute pyelonephritis and renal scarring. Pediatr Res 2003;53:698-705. 